\title{
Heterotopic ossification (HO) as a complication of Guillain-Barre syndrome (GBS): A case report
}

\author{
Avraam Ploumis*, Dimitrios Varvarousis, Areti Theodorou, Ioannis Gelalis, Anastasios Korompilias and Emilios Pakos \\ Department of Physical Medicine and Rehabilitation \& Orthopaedics, University of Ioannina, Ioannina, Greece
}

\begin{abstract}
Background: Heterotopic Ossification (HO) is usually associated to musculoskeletal trauma or neurological injury.

Case report: Our objective is to present a rare case of bilateral presence of $\mathrm{HO}$ in the hip joints in a patient with Guillain-Barre Syndrome (GBS) and compare it with other similar cases from the literature. Possible causative correlation of $\mathrm{HO}$ with different factors and effects on patients' functionality are also discussed.

Clinical rehabilitation impact: $\mathrm{HO}$ is a rare complication of patients with GBS and should be suspected early when causative factors exist, as it plays a major role in their functional outcome.
\end{abstract}

\begin{abstract}
Abbreviations: HO: Heterotopic ossification; GBS: Guillain Barre Syndrome.

\section{Introduction}

Heterotopic Ossification (HO), also known as Myositis Ossificans (MO), is a metabolic disorder of calcium that results in new lamellar bone formation mostly in muscles and soft tissue near the joints, outside the normal skeletal system. It is often a complication of Central Nervous System (CNS) injury, Spinal Cord Injury (SCI), brain injury and other non-traumatic CNS diseases, although less frequently [1-4].
\end{abstract}

Guillain-Barre syndrome (GBS) is an inflammatory polyneuropathy, often precipitated by infections and presents by ascending progressive weakness that eventually leads to flaccid paralysis. There may also be sensory symptoms, pain and autonomic involvement [5]. 80\% of the patients may achieve total or partial recovery, for $5 \%$ of them is fatal and $15 \%$ of the patients have neurologic and functional deficits.

$\mathrm{HO}$ is a rare complication of GBS [6], but when it's presented within GBS it can have an important impact on the functional recovery of the patients. In this paper we present an unusual case of GBS complicated with $\mathrm{HO}$ in both hips and compare it with similar cases from the literature, aiming to evaluate causative factors of $\mathrm{HO}$ in GBS patients.

\section{Case report}

\section{Patient information}

A 67-year-old, otherwise healthy, male was admitted to our hospital with weakness in the lower extremities that later also affected the upper extremities and gradual onset. The patient reported a previous viral upper respiratory tract infection. His past medical, family and psychological history was not significant of serious neurological or musculoskeletal illnesses.

\section{Clinical findings, Diagnostic assessment and Therapeutic intervention}

Head CT was clear and cerebrospinal fluid exam was not compatible with CNS infection $\left(0 / \mathrm{mm}^{3}\right.$ cells and $29 \mathrm{mg} / \mathrm{dl}$ protein). GBS was diagnosed and the patient started treatment with immunoglobulin ( $160 \mathrm{~g}$ for 5 days). Even with the treatment, the patient gradually deteriorated, and it was necessary to be intubated. Two months following his admission to ICU, he was disconnected from the respirator and one week later, he was also decannulated. A day later he was transferred back to the neurology clinic, where he started daily kinesiotherapy and respiratory physiotherapy. He was finally transferred to our clinic (PRM). At that time the labs showed increased alkaline phosphatase (ALP) (368 IU/L) and normal serum calcium $(9,3$ $\mathrm{mEq} / \mathrm{L}$ ). Radiographic imaging of the pelvis showed no evidence of $\mathrm{HO}$ (Figure 1a) but due to local inflammation of the hip area and elevated ALP he was started on indomethacin $75 \mathrm{mg}$ once daily for 6 weeks as well as etidronate $400 \mathrm{mg}$ twice daily for 3 months and once daily for another 3 months.

During his stay at our clinic, he continued with active assisted exercises of his hip with gradual sitting position, regular kinesiotherapy for the other joints of his extremities and swallow muscles exercises. Three months following admission, he regained muscle strength of his forearm and the Folley catheter was removed. In a new radiological assessment of pelvis and hips, $\mathrm{HO}$ was detected in the hip joints (most severe on the right) (Figure $1 \mathrm{~b}$ ) and was absent on both knees. The ALP

${ }^{*}$ Correspondence to: Avraam Ploumis, Department of Physical Medicine and Rehabilitation \& Orthopaedics, University of Ioannina, 45110 Ioannina, Greece, E-mail: aploumis@uoi.gr

Key words: heterotopic ossification, musculoskeletal trauma, neurological injury

Received: November 20, 2018; Accepted: November 30, 2018; Published: December 03, 2018 
remained increased almost throughout his stay in our clinic (range: 120-368 IU/L) and serum calcium remained within normal values.

On the fourth month after admission further improvement of his muscle strength in the upper and lower extremities and less in pelvis was observed. Serum ALP was decreased to normal. However, fixed flexion deformity (approximately 20 degrees) with difficulty in sitting and walking was evident.

\section{Follow-up and outcomes}

Although patient gradually improved and was discharged, simple radiologic imaging was performed again, and $\mathrm{HO}$ was even more evident (Figure 1c). The CT of the pelvis showed bone lateral and posterior to the hip joints bilaterally. Total time of follow-up was 12 months. Bone scan after 12 months showed improvement although $\mathrm{HO}$ was still immature (increased radionuclide uptake in both hip joints). The patient was scheduled for surgical excision of $\mathrm{HO}$ when bone scan will not show increased uptake.

\section{Discussion}

A case of heterotopic ossification (HO) in a patient with GuillainBarre Syndrome (GBS) is presented and the incidence, the influence on functionality and possible causative correlation between HO and GBS are also reported. In the literature, we found 13 cases of $\mathrm{HO}$ after GBS and including our case a total of 14 cases exist (Table 1). Zeilig et al. [5]

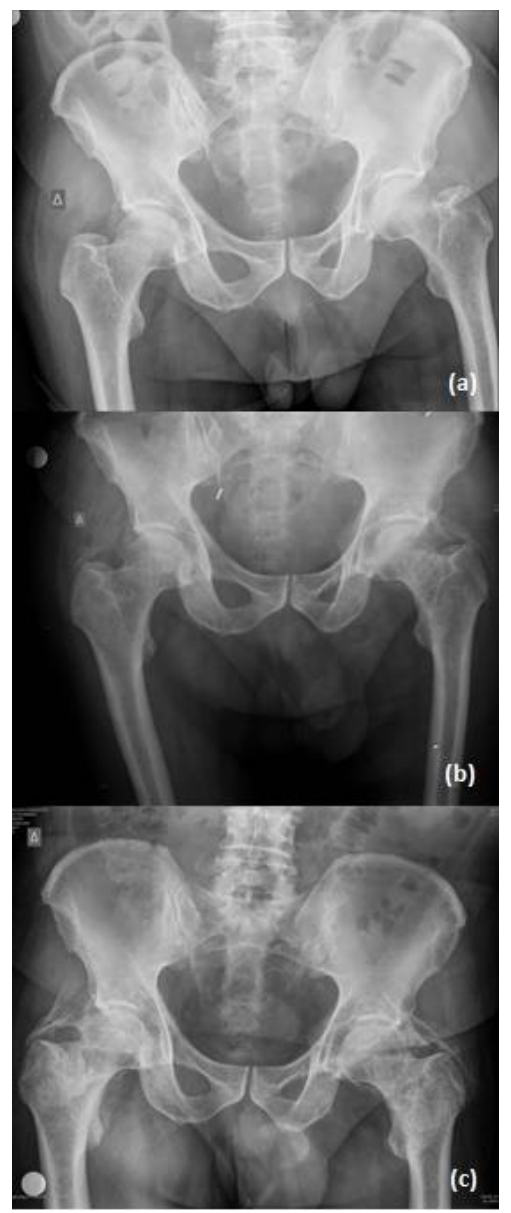

Figure 1. Simple radiologic imaging of the pelvis one month before HO diagnosis (a), on HO diagnosis (b), 4 months after diagnosis HO still present (c)
Table 1. Cases of HO after GBS

\begin{tabular}{|c|c|}
\hline Study & \# of cases \\
\hline Ryu SR et al. [7] & 1 \\
\hline Zeilig G et al. [5] & 4 \\
\hline Vaishya R et al. [9] & 1 \\
\hline Shawgi M [10] & 1 \\
\hline Kerdoncuff V et al. [6] & 3 \\
\hline Ohnmar H et al. [8] & 1 \\
\hline Bernard V & 1 \\
\hline Hung JCC et al. & 1 \\
\hline PMR clinic & 1 \\
\hline
\end{tabular}

reported a $4 \%$ incidence of $\mathrm{HO}$ in patients with GBS. The incidence of $\mathrm{HO}$ in our PMR clinic is less than 3\% (1 patient out of 40 GBS admitted patients over 11-year time period).

$\mathrm{HO}$ is a rare complication in the context of other neurologic disorders. It has been described more often following CNS trauma [2] and less frequently after other neurologic incidents. There has been a link between $\mathrm{HO}$ and peripheral nerve disorders, GBS included. Our patient was a male which happens to be the gender most commonly affected by HO after GBS ( $66 \%$ of cases). The mean age of the patients was 42 years old while our patient was 67 years old. The hip joint was more severely affected in our patient which is also in accordance with the international literature (7 out of 9 cases) [5-7].

Risk factors reported were mechanical ventilation $[5,8,9]$, prolonged immobilization [7-9] and hypoxia [5,8]. Our patient was only mechanically ventilated. One of the patients also had fixed flexion deformity $\left(15^{\circ}\right)$ [9]. Also, our patient had fixed flexion deformity and the typical signs of inflammation $[5,7,9]$.

Diagnostically simple radiologic imaging, 3-phase bone scan, MRI and SPECT/CT was used $[5,7,9,10]$. All these imaging techniques, except MRI, were performed in our patient.

Lab values reported were alkaline phosphatase, serum calcium and serum phosphate [5,7]. Of these, only alkaline phosphatase was mentioned to be increased, including our patient.

Treatment options consisted of medications, radiotherapy, surgery and rehabilitation therapy [5,7-9]. Our patient was treated with medications, rehabilitation therapy and will receive surgical treatment (excision of $\mathrm{HO}$ ) after reevaluation.

Zeilig et al. [5] and Kerdoncuff et al. [6] reported the time of followup, which varied between 6 months and 15 years. In the former study, patients presented on admission to rehabilitation requiring assistance for ADL and mobility. During the long-term follow-up, patients presented with affected posture and gait cycle due to severe limitations in hip ROM. In the latter study, the patient had permanent disability which was not cause by the $\mathrm{HO}$ rather than the neurologic sequelae of GBS. Shawgi et al. [10] also reported that their patient had improvement in the pain score despite the stiffness of the knees that was present throughout the follow-up. Kerdoncuff, et al. [6] also reported that their three patients had great functional handicap during the follow-up. Our patient has been followed for 12 months and has functional limitations in his postural and walking ability, but he did not complain of pain in the end of his follow-up.

\section{Conclusion}

A unique complication of $\mathrm{HO}$ in a patient with GBS and a systematic literature review is presented. Physicians (and therapists) should suspect $\mathrm{HO}$ in symptomatic (related to large joints) patients with GBS when risk factors exist. 


\section{Conflicts of interest}

The authors declare no conflict of interest.

\section{Funding}

No financial support/equipment/drugs have been received for this work

\section{Authors Contributions}

AP,DV,AT Conceived and/or designed the work that led to the submission, acquired data, and/or played an important role in interpreting the results.

AP, DV, AT Drafted or revised the manuscript.

AP, IG, AK Approved the final version

\section{Contributors}

No

\section{Congresses}

56th ISCoS Annual Scientific Meeting, Dublin, Ireland

\section{Acknowledgements}

No

\section{References}

1. Sell S, Phillips O, Handel M (2004) No difference between two doses of diclofenac in prophylaxis of heterotopic ossifications after total hip arthroplasty. Acta Orthop Scand 75: 45-49. [Crossref]

2. Van Kuijk AA, Geurts AC, van Kuppevelt HJ (2002) Neurogenic heterotopic ossification in spinal cord injury. Spinal Cord 40: 313-326. [Crossref]

3. Garland DE (1991) A clinical perspective on common forms of acquired heterotopic ossification. Clin Orthop Relat Res 263: 13-29. [Crossref]

4. Wharton GW (1975) Heterotopic ossification. Clin Orthop Relat Res 142-149. [Crossref]

5. Zeilig G, Weingarden HP, Levy R, Peer I, Ohry A, et al. (2006) Heterotopic ossification in Guillain-Barre syndrome: incidence and effects on functional outcome with longterm follow-up. Arch Phys Med Rehabil 87: 92-95. [Crossref]

6. Kerdoncuff V, Sauleau P, Petrilli S, Duruflé A, Ben Beroukh K, et al. (2002) Heterotopic ossification in Guillain-Barre syndrome. Ann Readapt Med Phys 45: 198203. [Crossref]

7. Ryu SR, Kim JH, Choi IS, Han JY, Lee SG (2008) Heterotopic ossification as an unusual complication after Guillain-Barre syndrome: a case report. Arch Phys Med Rehabil 89: 564-567. [Crossref]

8. Ohnmar H, Roohi SA, Naicker AS (2010) Massive heterotopic ossification in GuillainBarre syndrome: a rare case report. Clin Ter 161: 529-532. [Crossref]

9. Vaishya R, Agarwal AK, Vijay V, Vaish A (2016) Heterotopic Ossification Circumferentia Articularis (HOCA) of Both Knee Joints After Guillain-Barre Syndrome. Cureus 8: e480. [Crossref]

10. Shawgi M (2012) Heterotopic ossification of the hips in a patient with Guillain Barre syndrome demonstrated on SPECT/CT. Clin Nucl Med 37: e253-254. [Crossref]

Copyright: $(02018$ Ploumis A. This is an open-access article distributed under the terms of the Creative Commons Attribution License, which permits unrestricted use, distribution, and reproduction in any medium, provided the original author and source are credited. 